\title{
PERSONAL DESIGN, THE NEW FASHION TREND BASED ON INNOVATIVE TECHNOLOGY
}

\author{
TRAIAN FOIAŞI \\ INCDTP - Division Leather and Footwear Research Institute, 93 Ion Minulescu, Sector 3, \\ Bucharest,icpi@icpi.ro
}

\begin{abstract}
Fashion design expresses not only a new idea in the creation of a product but also its identification with the person wearing it. Thus arises the notion of personal design, which will be increasingly used in the coming years. Everything will become a cultural communication through the message that the product idea sends, a technological communication through technical drawings of the product, a commercial communication through the collection and advertising by fashion illustration. These clues will express the wearer's personality, will emphasize certain features and blur others, and will enable them to recompose the specific elements of the product. The concept of personal design has rapidly evolved and is complementary to mass production and even a competitor for haute couture. Elements of innovation and performance are not only a set of new knowledge in the field but also a real tool to correctly assess the creative opportunities of footwear companies and develop product strategies. The idea or concept sketches are a graphic illustration of the product, a mandatory work instrument in all phases of design and in all its manifestations. New technologies and the growing involvement of the "fashion customer" lead to the emergence of new architectures in the aesthetic and emotional expression of the wearer. Some topics will reveal each form of characters' identification with the product through concept drawings.
\end{abstract}

Keywords: personal design, fashion, trend

\section{INTRODUCTION}

Fashion design expresses not only a new idea in the creation of a product but also its identification with the person wearing it. Thus arises the notion of personal design, which will be increasingly used in the coming years.

Everything will become a cultural communication through the message that the product idea sends, a technological communication through technical drawings of the product, a commercial communication through the collection and advertising by fashion illustration. These clues will express the wearer's personality, will emphasize certain features and blur others, and will enable them to recompose the specific elements of the product.

The concept of personal design has rapidly evolved and is complementary to mass production and even a competitor for haute couture.

Fashion and technology are two words that go together very well. And this is only the beginning, because high-tech will continue to transform what we wear, in many ways, in the years to come. 3D printing technology is still in its infancy, but has already made its way into the fashion world.

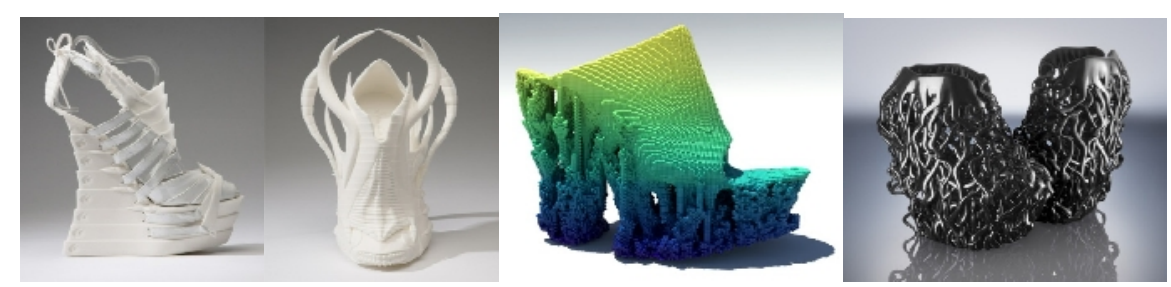

Figure 1. Footwear designed using 3D technology 
Personal Design, the New Fashion Trend Based on Innovative Technology

In the future we will see increasingly more shoes with a unique design. Product development and innovation are an important part of the design process. Following the stages in the process design, after having defined the new product concept, it seems necessary to diversify (elaborate) this product idea.

Diversification techniques (product development) aim to obtain a sufficient number of models within the same family (concept), models that undergo an analysis that aims to define the best solutions both for the consumer and for the producer.

\section{EXPERIMENTAL}

Elements of innovation and performance are not only a set of new knowledge in the field but also a real tool to correctly assess the creative opportunities of footwear companies and develop product strategies. The idea or concept sketches are a graphic illustration of the product, a mandatory work instrument in all phases of design and in all its manifestations. New technologies and the growing involvement of the "fashion customer" lead to the emergence of new architectures in the aesthetic and emotional expression of the wearer. Some topics will reveal each form of characters' identification with the product through concept drawings (Figures 2-11).

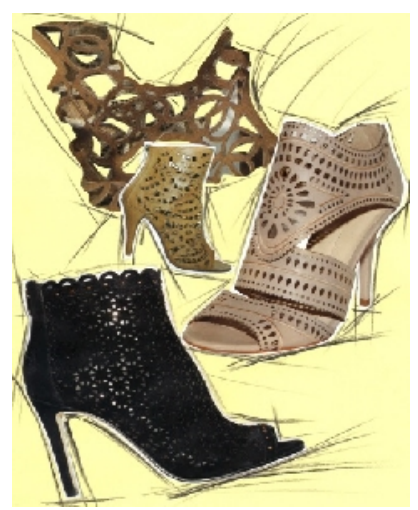

Figure 2. Lacework and perforations made using laser cutting provide elegance and preciousness to the proposed models

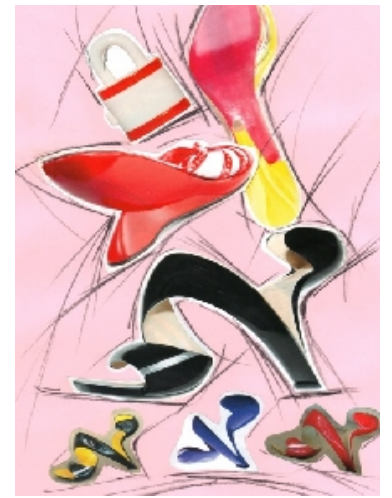

Figure 3. Innovative technologies allow carbon models with a futuristic and sophisticated look 
ICAMS $2016-6^{\text {th }}$ International Conference on Advanced Materials and Systems

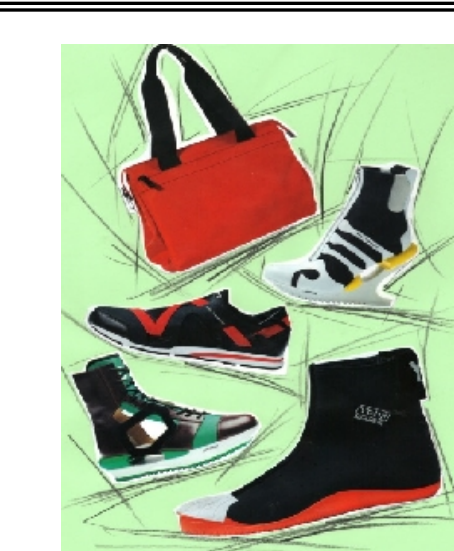

Figure 4. Creating high-tech hybrid materials with sophisticated effects heading to the sports style area

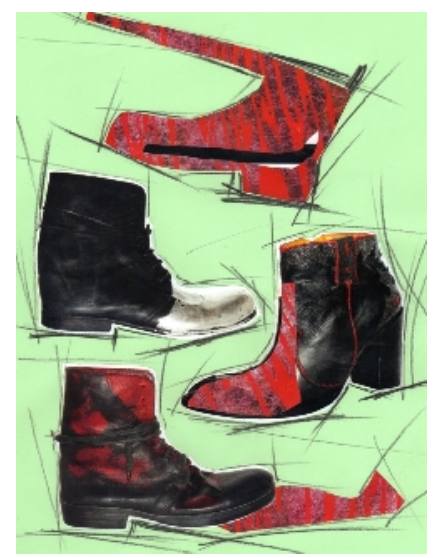

Figure 6. Hand painted shoes with metallic and matte, shiny and opaque effects are a particular area of the exclusive market

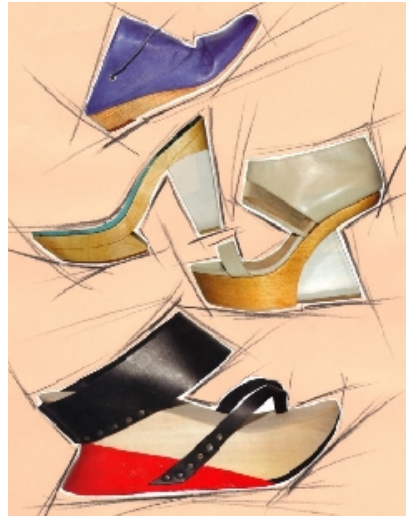

Figure 5. Returning to nature and environmentalism are desiderata with a great involvement on the part of designers who create spectacular shapes out of wood.

"Wood Effect" is part of personal design.

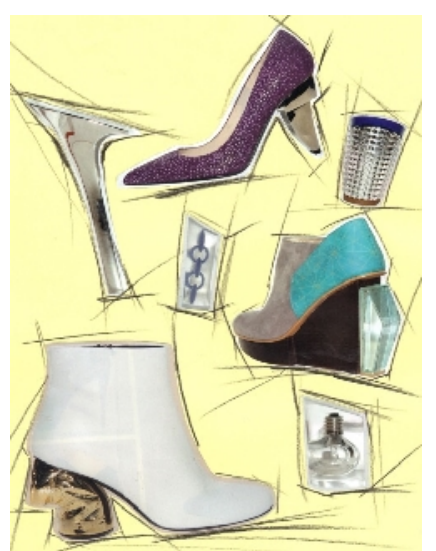

Figure 7 . The elegance and angular brightness transparencies undoubtedly spark the joy of wearing a shoe with personality 


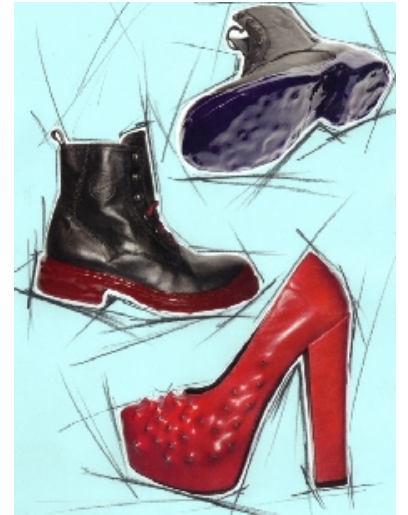

Figure 8. High class technologies are increasingly prominent by producing protective materials that stand out by applying films (elastomer) that give a particular and nonconformist look

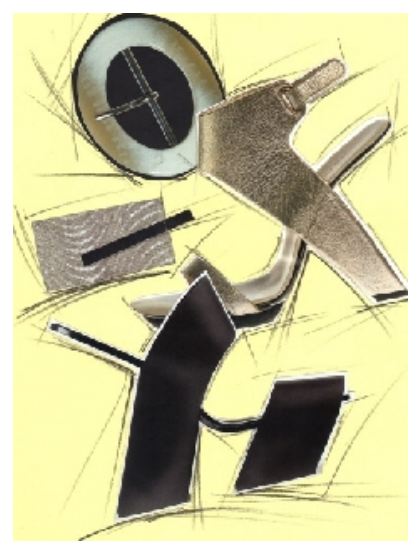

Figure 10. Inspired by the surrounding space with analytical geometry, discovering the essence, architectural forms that defy conventionality are recomposed

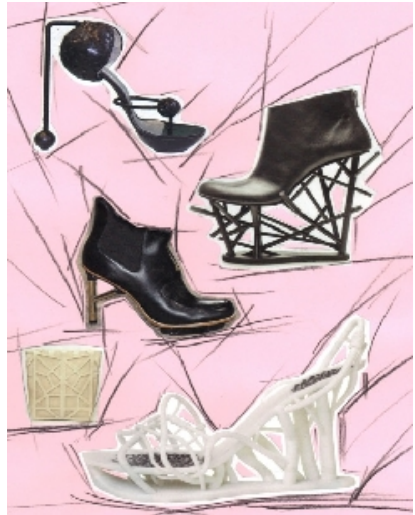

Figure 9. The perceptible space is an area of excellence for designers who have created a performance of footwear creations using 3D technology

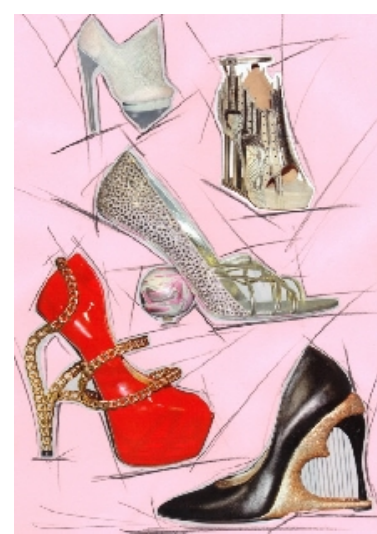

Figure 11. Creativity and passion, terms that define designer footwear with a great cultural impact, turning into real items of exhibition

\section{DISCUSSIONS}

The impact 3D printers will have on society is difficult to predict, however, several important effects have already begun to take shape. Thus, at the moment most of the products are made in countries with the lowest production costs, and are then transported all over the world. Thanks to 3D printers, the products will be created where 
ICAMS $2016-6^{\text {th }}$ International Conference on Advanced Materials and Systems

the customers are, and the ability to customize designs depending on the customer's taste will, in some cases, eliminate the need for mass production.

Producers' optimism is justified by the huge potential this technology offers and its anticipated accelerated development. Although implementation is running slow, we already see how 3D printing influences all areas.

The pragmatic approach to the relationship of design, technology, and image becomes a scientific instrument for the production of ideas that define the personality of a category of products, its demand on the market and the chances of success compared to other products.

Aesthetic design of a new product involves creative spirit and artistic talent; the designer must find the optimal shape of the new product. This shape must, however, match the improved functionality of the product.

Improving the functionality of the designed product requires implementation of results from various fields of science and technology.

\section{CONCLUSIONS}

Design focuses on investigations in many areas and is provided by a multidisciplinary team, directed and coordinated by an expert designer, who conducts the study of all product components in terms of design, manufacture and market promotion.

This process has implications in various fields of science and technology: research, engineering, engineering design, economics, ergonomics, psychology, sociology, economics, marketing, finance, ecology, law, semiotics, public services etc.

The activity of the design industry can be defined as a harmonization of the relationship between people and objects, between the environment and the messages they come in contact with, exerting a positive influence on quality of life.

\section{REFERENCES}

*** (2015), Ars Sutoria, no. 392, Milano, Italy.

*** (2015), Ars Sutoria, no. 398, Milano, Italy.

*** (2015), Ars Sutoria, no. 399, Milano, Italy.

*** (2015), Ars Sutoria, no. 401, Milano, Italy.

*** (2015), Ars Sutoria, no. 402 bis, Milano, Italy.

*** (2015), Ars Sutoria, no. 406, Milano, Italy.

Katrantzou, M. (2012), "Technological Innovations in Fashion”, Art Act Magazine, available at http://artactmagazine.ro/mary-katrantzou-inovatii-tehnologice-in-moda.

Maslow, A.H. (2006), Motivation and personality, London. 
Personal Design, the New Fashion Trend Based on Innovative Technology 